\title{
Criteria for assessing the suitability of intended surrogate mothers in South Africa: Reflections on Ex Parte KAF II
}

\author{
D W Thaldar, BLC, LLB, MPPS, PhD, PGDip (Strategy and Innovation) \\ School of Law, Howard College, University of KwaZulu-Natal, Durban, South Africa, and associate member, KwaZulu-Natal Bar, South Africa
}

\section{Corresponding author: DW Thaldar (ThaldarD@ukzn.ac.za)}

\begin{abstract}
In order to protect the interests of all parties involved in a surrogacy agreement as best as possible, what should the psychological profile of a surrogate mother be? This is the question that the Johannesburg High Court recently engaged with in the case of Ex Parte KAF II. The court had the benefit of a psychological expert opinion co-authored by three clinical psychologists. In their joint opinion, these experts suggested an answer to the question in the form of eight criteria for assessing the suitability of an intended surrogate mother. The surrogate mother should: (i) understand the nature of surrogate motherhood; (ii) agree with the commissioning parents regarding selective reduction; (iii) be motivated by altruism; (iv) enjoy good mental health; ( $v$ ) be emotionally well-resourced; (vi) be emotionally available for her own child or children; (vii) be free of unhealthy substances; and (viii) be financially stable. Although reformulated, these eight criteria were effectively adopted by the court, thus creating a new precedent to be followed by clinical psychologists who provide reports to the court in future surrogacy cases.
\end{abstract}

S Afr J Bioethics Law 2019;12(2):61-65. https://doi.org/10.7196/SAJBL.2019.v12i2.670

In South Africa, surrogate motherhood is regulated by Chapter 19 of the Children's Act, ${ }^{[1]}$ which came into effect in 2010. The most salient aspects of the regulatory system are that surrogacy must be altruistic, and that a surrogacy agreement should be pre-approved by the high court before the artificial fertilisation of the surrogate mother can commence. If a surrogacy agreement is confirmed by the court, and provided that the surrogate mother's own eggs are not used, the child that is born in pursuance of the surrogacy agreement will be legally deemed to be the child of the commissioning parent(s) from the moment of birth. In this respect, surrogacy therefore stands in contrast to adoption, which is a process that can only commence after the birth of a child, and which is subject to several contingencies that are inimical to legal certainty. The very purpose of the preapproval mechanism for surrogate motherhood is to establish legal certainty for all the parties involved - including the child that is to be born. ${ }^{[2]}$ In a way, a surrogacy agreement confirmation hearing is a way to pre-empt any possible disputes, by forcing the parties to properly consider and find solutions to reasonably foreseeable events.

The pre-approval mechanism for surrogate motherhood depends heavily on input from clinical psychologists. The court requires psychological reports to be filed on the intended commissioning parent(s) and the intended surrogate mother. ${ }^{[3]}$ Typically, it is the psychological assessment of the intended surrogate mother that receives the most attention from assessing clinical psychologists and the courts. The reason is apparent: while commissioning parents are motivated by the near-universal desire to have a child, it is extraordinary for a woman to offer to gestate somebody else's child without any financial compensation. The problem is that - until recently - there were no general, objective criteria according to which intended surrogate mothers could be assessed. The Children's Act only provides that a surrogate mother must be a 'suitable' person (section 295(c)(ii)). It does not provide further clarity regarding what exactly is meant by a 'suitable' person. In a recent judgment, Ex Parte KAF II, ${ }^{[4]}$ the Johannesburg High Court recognised the problem and made a brave attempt to address it. This judgment, and its contribution to the psychological assessment of intended surrogate mothers, are the focus of this article.

\section{Background to the case}

The commissioning mother and father, and the surrogate mother and her fiancé (the applicants) first approached the Johannesburg High Court to confirm their surrogacy agreement in 2017. ${ }^{[5]}$ However, one major concern raised by the court was the suitability of the surrogate mother, ND. The court's concern stemmed from the fact that ND, who was 20 years old at the time of the court application, had had a teenage pregnancy at the age of 16 . Although the applicants filed a psychological expert opinion that dealt with ND's suitability to act as a surrogate mother and that made a positive finding in this regard, the court in fact rejected this finding. The court, per Modiba J, held that it was not satisfied that ND had the maturity to appreciate the implications of her life decisions, and dismissed the applicants' surrogacy agreement confirmation application. This disjunction between the psychologist and the court demonstrated the need to authoritatively establish a set of objective criteria to assess the suitability of an intended surrogate mother - a set of criteria to be applied by both the assessing clinical psychologist and the court. ${ }^{[6]}$

In 2018, the same applicants again approached the Johannesburg High Court to confirm their surrogacy agreement - this time with supplemented papers. ${ }^{[4]}$ The legal strategy of the applicants was to confront the issue of ND's suitability to be a surrogate mother by: (i) suggesting a set of general, objective criteria to assess the suitability of any surrogate mother, and then (ii) to apply these criteria to ND 
specifically. To accomplish (i), the applicants filed a joint psychological expert opinion ('joint opinion') by three clinical psychologists, each of whom had extensive experience in the assessment of prospective surrogate mothers. In their joint opinion, the clinical psychologists identified and discussed eight main criteria to assess the suitability of a surrogate mother. These are discussed below. To accomplish (ii), the applicants filed a psychological expert opinion by a fourth clinical psychologist (the assessing psychologist), who was tasked with re-assessing ND in light of the criteria suggested by the joint psychological expert opinion. The assessing psychologist also focused on the issue that had caused concern to the court in 2017 - namely ND's teenage pregnancy. In this regard, the assessing psychologist observed that it would be 'unfair and not reality-based' for ND to be measured by her previous, 16-year-old self, and that ND had since evolved into an emotionally mature woman. Applying the criteria suggested in the joint psychological expert opinion, the assessing psychologist concluded that ND was indeed suitable to be a surrogate mother. This time around, the Johannesburg High Court, per Siwendu J, agreed with the psychological assessment, and confirmed the applicants' surrogacy agreement.

Importantly, the Johannesburg High Court in Ex Parte KAF II took up the challenge of establishing general, objective criteria to assess the suitability of an intended surrogate mother - a significant development of the law regarding surrogacy, and of particular relevance to clinical psychologists and legal professionals who deal with surrogacy.

\section{Criteria to assess the suitability of a surrogate mother}

The experts who co-authored the joint opinion suggested eight criteria to assess the suitability of an intended surrogate mother. These eight criteria had a significant influence on the judgment in Ex Parte KAF II. In fact, the court stated that it had received 'valuable assistance' from the joint opinion. Many of the criteria laid down by the court are a reformulation or restructured version of the original eight criteria. However, there are also differences in terms of content and emphasis between the joint opinion and the judgment. In the analysis below, I highlight these similarities and differences.

The court lists the criteria that it decided on in paragraphs 27 to 29 of the judgment. ${ }^{[4]}$ It is clear that the court's intent was that these paragraphs contain the criteria for assessing the suitability of an intended surrogate mother (see paragraph 34). I therefore refer to these criteria as the judgment's 'list' of criteria. However, the court does not state that this list of criteria is exhaustive, and an earlier part of the judgment (paragraph 11) can be interpreted as implicitly adding an additional criterion for assessing the suitability of an intended surrogate mother. ${ }^{[4]}$

In the following analysis, I use the original eight criteria as per the joint opinion as a point of departure - rather than the judgment's list. My reasons for choosing this structure will become evident from the analysis below.

\section{Criterion 1: A suitable surrogate mother must understand the nature of surrogate motherhood}

The first criterion suggested in the joint opinion was that a suitable surrogate mother must understand the nature of surrogate motherhood, namely that she will carry a baby on behalf of the commissioning parents and that the baby she will give birth to will legally not be her child, but the child of the commissioning parents. This criterion was adopted by the court in paragraphs 29 and 29.3 of the judgment. ${ }^{[4]}$

\section{Criterion 2: There must be agreement between the parties regarding selective reduction}

Given that multiple embryos may be transferred to a surrogate mother's uterus, there is an increased chance of a multiple pregnancy. However, the commissioning parent(s) may not desire to have multiples, and may want the surrogate mother to undergo a so-called 'selective reduction'. Selective reduction is the selective abortion of embryos in a pregnant woman's womb to reduce the embryos in the pregnancy to a desired number, such as one or two. In the joint expert opinion, the clinical psychologists stated that it is essential that there must be 'perfect alignment' between the intended surrogate mother's intentions and the commissioning parents' intentions regarding selective reduction. They suggested that the assessing clinical psychologist should ensure that the prospective surrogate mother understands the concept of selective reduction, and that there is consensus between all parties involved on whether selective reduction will be used or not. The court included this criterion (paragraph 27.2), and added that the surrogate mother must also understand the risks involved. ${ }^{[4]}$ Given that the court did not specify whether it had physical or psychological risks in mind, it is safe to assume both. This means that the assessing clinical psychologist should be familiar not only with the potential psychological sequelae of selective reduction, but also with potential medical sequelae.

\section{Criterion 3: A suitable surrogate mother must be motivated by wanting to help the commissioning parents without expectation of reward}

Altruism is at the core of the legislative scheme for surrogate motherhood. As such, it is suggested in the joint opinion that a suitable candidate must be motivated by wanting to help the commissioning parents - without expectation of reward. The expert clinical psychologists who co-authored the joint opinion specifically dispelled the notion that a surrogate mother should be an altruistic person in general. They observed that although surrogate mothers are often generous and compassionate people in general, such general altruism should not be essential. What should be required, in their opinion, is altruism toward the commissioning parents in particular. They also sought to clarify the popular idea that a surrogate mother should 'enjoy pregnancy', by differentiating between the symptoms of pregnancy and the idea of pregnancy as growing a new life. They suggested that while enjoying the symptoms of pregnancy may border on the pathological, surrogate mothers enjoy the idea of growing a life for the commissioning parents.

In Ex Parte KAF II, the court mentioned ND's altruistic motivation only in passing, and did not include altruistic motivation in its list of general criteria for assessing the suitability of a surrogate mother. Rather than focus on ND's subjective motivation, the court appeared to focus on something more objective, namely the budget for out-ofpocket expenses for which the commissioning parents would have to reimburse ND as the surrogate mother. The apparent inference is that the actual agreement regarding reimbursable expenses is the only relevant consideration on which altruism will be judged, and that an 
intended surrogate mother's motivation for engaging in surrogacy is not legally relevant.

I suggest that the court's omission of an intended surrogate mother's motivation from its list of general criteria is regrettable, for the following reason: in the event that a surrogate mother's motivation is specifically not altruistic, this constitutes a real risk of her attempting to elicit unlawful (beyond the initially agreed) benefits from the commissioning parents during the surrogacy pregnancy. As such, from a risk-mitigation perspective, assessing clinical psychologists should continue the well-established practice of probing an intended surrogate mother's motivation for wanting to be a surrogate mother.

There is an important caveat - something that can be learned from the Ex Parte KAF II judgment: Motivation as expressed by an intended surrogate mother during consultation with the assessing clinical psychologist must of course be aligned with the reality of the financial provisions of the surrogacy agreement. Which out-of-pocket expenses are reimbursable, and to what amount such expenses are reimbursable, can differ from situation to situation, but it is instructive to keep the figures in mind that the court approved in Ex Parte KAF II, as they can be used as an authoritative benchmark. These figures are presented in Table 1. The following should be noted:

- Given that ND was a housewife, loss of income was not relevant. In cases where the surrogate mother is employed, compensation for maternity leave may be relevant.

- Travel to clinics and hospitals is typically a reimbursable out-ofpocket expense that is uncapped. This was also the case in Ex Parte KAF II.

- The commissioning parents would typically be directly responsible for the surrogate mother's medical costs and insurance. Life and disability insurance on ND to the value of ZAR1 million was to be taken out by the commissioning parents.

\section{Criterion 4: A suitable surrogate mother must enjoy good mental health}

The expert clinical psychologists who co-authored the joint opinion suggested that a suitable surrogate mother must enjoy good mental health, and not suffer from any personality disorder or severe psychiatric illness, or have a history of self-harming behaviour. The court incorporated this criterion into its list of general criteria for assessing the suitability of a surrogate mother (in paragraph 27.3 of the judgment). ${ }^{[4]}$

\section{Criterion 5: A suitable surrogate mother must be emotionally well-resourced}

The criterion suggested in the joint opinion that apparently made the biggest impression on the court is that a suitable surrogate mother must be emotionally well-resourced. This criterion appears in some form or another in no less than eight places in the court's list of general criteria for assessing the suitability of a surrogate mother (in paragraphs 28, 28.1, 28.2, 28.3, 28.4, 29.1, 29.2 and 29.5 of the judgment) ${ }^{[4]}$ However, it is important to clarify what was meant in the joint opinion by the concept 'emotionally well-resourced', as this is not made explicit in the judgment. In the joint opinion, the experts state that by 'emotionally well-resourced', they mean that a surrogate mother 'must either be emotionally self-reliant, or have a ready and established emotional support structure'. Emotional self-reliance, they explain, is evident from having a mindset that one's emotional wellbeing is primarily one's own responsibility, and from not being easily or unduly influenced by the opinions of other people. An emotionally self-reliant person, according to the experts, must have the cognitive ability to value constructive criticism and to disregard malicious feedback. However, they recognise that many people are less emotionally self-reliant than this, and rather rely on others for emotional support. Surrogate mothers, the experts point out, need not be exceptions in this regard: they can rely on a partner or spouse, family, work colleagues and/or friends for emotional support.

An important aspect of the joint opinion regarding this criterion is that the popular notion that a surrogate mother must always have supportive family should not be a requirement - at least not in all cases. For instance, it is entirely conceivable that a woman's decision to act as a surrogate mother might be opposed (informally, not legally) by her parents and siblings, but that she happens to be emotionally distanced and practically independent from them, so rendering their opposition psychologically insignificant. One of the criteria formulated by the court (paragraph 28.4) specifically requires an analysis of whether 'surrounding relationships' are conducive for the surrogate mother's compliance with the surrogacy agreement, and another essentially similar criterion (paragraph 29.5) requires an analysis of whether the 'psychosocial support structure' is likely to result in a breach of the surrogacy agreement. ${ }^{[4]}$ These criteria should therefore not be interpreted as simplistically implying that all the people in a woman's family or friendship circle must necessarily support her decision to act as a surrogate mother; rather, the nature and intensity of support or opposition from family and friends should be interpreted in the light of the importance of these relationships to the surrogate mother, and in light of the surrogate mother's own personality - in particular, her degree of emotional self-reliance.

Related to the above is the criterion formulated by the court (paragraph 29.2) that an assessing clinical psychologist must report on 'the understanding and influence of the spouse, partner, relatives or extended family on the decision [to be a surrogate mother]. ${ }^{[4]}$ Does this criterion mean that an assessing clinical psychologist must investigate whether an intended surrogate mother's entire extended family knows about and understands her decision, and whether they influenced the decision? This would clearly be going too far as a

Table 1. Budget for reimbursable expenses of surrogate mother approved in Ex Parte KAF $\mathrm{II}^{[4]}$

\begin{tabular}{|c|c|c|}
\hline Expense & Amount (ZAR) & Period \\
\hline Cellular phone calls & 500 per month & From the confirmation of the surrogacy agreement until the birth of the child \\
\hline $\begin{array}{l}\text { Vitamins, nutritional supplements and scar } \\
\text { creams }\end{array}$ & 1500 per month & For the duration of the pregnancy \\
\hline Domestic worker & 3500 per month & From the onset of pregnancy, until 3 months thereafter \\
\hline Maternity clothing & 6750 & This amount is not per month, but for the duration of the pregnancy \\
\hline
\end{tabular}


general rule. A more reasonable interpretation of this criterion would be to ascertain the understanding and influence of people in an intended surrogate mother's social surroundings, to the extent that such people actually play a role in her life.

The judgment points out that according to section 293(2) of the Children's Act, the surrogate mother's spouse or, if she is unmarried but in a permanent relationship, her partner, must consent in writing to the surrogacy agreement. However, there are two riders that did not get attention in the judgment: firstly, this legal requirement concerns only the spouse or partner, and cannot be extrapolated to include other persons in the surrogate mother's social surroundings. Secondly, the very next subsection of the Children's Act, section 293(3), provides that where a spouse or partner who is not the genetic parent of the child unreasonably withholds consent, the court may still confirm the agreement. This scenario was not relevant in Ex Parte KAF I and II, as ND's fiancé was supportive of her, and was therefore not mentioned in either the joint opinion or the judgment. However, the rider in section 293(3) is important, in the event that such a scenario should arise.

\section{Criterion 6: A suitable surrogate mother must be emotionally available for her own child or children}

The Children's Act requires that a surrogate mother must have at least one living child of her own. In the joint opinion, the experts suggested that any pregnancy - whether a surrogate pregnancy or not - affects a mother's child or children. In order to protect the emotional welfare of a mother's child or children, the experts suggested that it is important that an intended surrogate mother must be emotionally available for her own child or children. This, according to the experts, includes readiness to discuss the surrogate pregnancy with her child or children, depending on their ages and levels of comprehension. This criterion was adopted by the court in its original formulation (in paragraph 29.6 of the judgment). ${ }^{[4]}$

\section{Criterion 7: A suitable surrogate mother must not engage in substance abuse of any kind, and must undertake to refrain from drinking alcohol or smoking during the pregnancy}

In the joint opinion, the experts suggested that a suitable surrogate mother must not engage in substance abuse of any kind, and must undertake to refrain from drinking alcohol or smoking during the pregnancy. This criterion only partially made it into the judgment (in paragraph 27.4). ${ }^{[4]}$ The court focused only on substance abuse, but was silent on the social drinking of alcohol and smoking during the pregnancy. Can a woman who smokes and who is not prepared to stop smoking for the duration of the pregnancy be viewed as a suitable surrogate mother? In the joint opinion, the experts went as far as suggesting that if an intended surrogate mother smokes, she must: (i) refrain from smoking for at least three months prior to conception; (ii) submit a blood test result to indicate that she stopped smoking; (iii) undertake to refrain from smoking for the duration of the pregnancy; and (iv) be free of any medication that she may use to stop smoking, unless authorised by the attending gynaecologist. Social drinking of alcohol and smoking are not 'substance abuse', but if a pregnant woman engages in these practices, it can be harmful to a fetus. The fact that these practices have not been mentioned by the court constitutes a regretful omission, which will hopefully be addressed in future cases.

\section{Criterion 8: A suitable surrogate mother must be financially stable}

In Ex Parte KAF I, the court raised the concern that ND might be engaging in surrogacy for financial gain. The court based its concern on a municipal statement for the property where ND and her fiancé were staying with the fiancé's family, which showed that payment for water and electricity was about ZAR15 000 in arrears. Although this issue was clarified to the court's satisfaction in Ex Parte KAF II, it raises the question: in the event that an intended surrogate mother is experiencing financial difficulties, does such a fact per se render her unsuitable to be a surrogate mother? In their joint opinion, the experts argue as follows:

'A surrogate mother who is in financial dire straits raises the concern that she may be engaging in surrogacy with the hope of financial gain, which would be contrary to the altruistic intention of the legislature. Even if this is not the surrogate mother's intention, her financial woes may later during the pregnancy cause undue tension in her relationship with the commissioning parents, who may be placed in an unenviable position where they feel that they must choose between their feeling of moral obligation and sympathy towards the surrogate mother on the one hand, and their legal duty not to give her any gifts on the other hand. This situation should of course be avoided.'

Therefore, as a risk-mitigation strategy, the experts suggest that an intended surrogate mother should be financially stable, meaning that she or her family unit must: (i) have a reliable source of income; and (ii) be living within her or their means. Although the court did not incorporate this criterion into its list of general criteria, it did apply the experts' suggestion in this regard almost verbatim in another part of the judgment (paragraph 11), where the issue of reimbursable expenses was considered. ${ }^{[4]}$ Similar to the altruistic motivation criterion that was suggested in the joint opinion, but omitted from the court's list of general criteria, risk mitigation should serve as a sufficient reason for assessing clinical psychologists to probe and report on the financial stability of an intended surrogate mother.

\section{Discussion}

The main issue with the judgment in Ex Parte KAF II that detracts from its practical utility is that many criteria are vaguely formulated to the point of being merely factors for consideration, and lacking any clear standard that must be complied with. Take, for instance, the purported criterion (in paragraph 28.2) that there must be a report on 'existing emotional resources.'[4] It does not state that there must be compliance with any substantive standard (such as having sufficient emotional resources in the context of her own personality and social surroundings), but simply that there must be a report on this topic. By adding factors for consideration without indicating exactly how such factors should impact on the overall assessment of suitability, the court is not solving the problem of uncertainty regarding how 
to assess suitability. In fact, the court is creating additional loci of uncertainty. Had the court retained the original wording of the joint opinion, this issue could have been avoided, as the eight criteria suggested in the joint opinion were all formulated as actual criteria standards that must be complied with.

The court's reformulation of the original eight criteria is also problematic in that it broke down some of the criteria suggested in the joint opinion into several overlapping and seemingly repetitive factors. The overlap between 'existing emotional resources', 'quality and stability of the existing emotional support structure' and 'psychosocial support structure' (paragraphs 28.2, 28.3 and 29.1) is apparent. ${ }^{[4]}$ This lack of discreteness of the factors listed by the court further detracts from the practical utility of the judgment.

Apart from reformulating the criteria suggested in the joint opinion (with less than optimal results), the court also added a criterion namely that the intended surrogate mother must be 'physically and medically fit' to carry the pregnancy successfully (paragraph 27.1). ${ }^{[4]}$ It is already established law that a medical specialist must provide a report to indicate whether surrogacy would pose any dangers to the intended surrogate mother or the child. ${ }^{[3]}$ This criterion is clearly beyond the remit of a psychological assessment, and was presumably only included by the court in an effort to make the judgment's list of criteria as comprehensive as possible. Clarity would have been better served had the court kept this criterion separate from the psychological criteria.

\section{Conclusion}

Ex Parte KAF II is a noteworthy development in our law relating to surrogate motherhood: the court recognised a problem, and pointed a way to a solution. The court had the benefit of a joint expert opinion co-authored by three clinical psychologists who were experienced in assessing intended surrogate mothers. However, the way in which the court reformulated the eight criteria suggested in the joint opinion does not optimally serve the purpose of the criteria - namely to achieve greater clarity regarding what exactly is meant by a 'suitable' person. As I have done in the analysis above, it would be more practical for assessing clinical psychologists to structure their reports on the suitability of an intended surrogate mother according to the eight criteria suggested in the joint opinion. Given that the joint opinion's eight criteria broadly correspond with the judgment's list of criteria, using the joint opinion's criteria will be aligned with and carry the authority of the new legal precedent created in Ex Parte KAF II. However, in contrast with the court's own reformulated criteria, the joint opinion's eight criteria are more discrete, and provide clear standards that must be complied with.

Lastly, while the eight criteria suggested in the joint opinion offer a useful and practical tool for assessing clinical psychologists, they should also be the subject of ongoing and rigorous academic analysis. How can these criteria be improved? It should be kept in mind that academic debate on the subject can influence the court in future cases. In fact, every surrogacy application before the high court offers the opportunity to develop and refine the law - even a seemingly obscure case involving an intended surrogate mother who had previously had a teenage pregnancy.

Declaration. The author was legal counsel for the applicants in Ex Parte KAF II. Acknowledgements. None.

Author contributions. Sole author.

Funding. None.

Conflicts of interest. None.

1. South Africa. Children's Act No. 38 of 2005. Retrieved from https://www.gov.za/ sites/default/files/a38-05.pdf (accessed 14 November 2019).

2. Ex Parte MS [2014] ZAGPPHC 457. http://www.saflii.org/za/cases/ZAGPPHC/2014/457. html (accessed 14 November 2019).

3. Ex Parte WH [2011] ZAGPPHC 185, 2011 (6) SA 514 (GNP). http://www.saflii.org/ za/cases/ZAGPPHC/2011/185.html (accessed 14 November 2019).

4. Ex Parte KAF [2018] ZAGPJHC 529, 2019 (2) SA 510 (GJ). http://www.saflii.org/za/ cases/ZAGPJHC/2018/529.html (accessed 14 November 2019).

5. ExParteKAF [2017]ZAGPJHC227.http://www.saflii.org/za/cases/ZAGPJHC/2017/227. html (accessed 14 November 2019).

6. Thaldar DW. The need to develop objective criteria for suitability as a surrogate mother: Reflections on Ex Parte KAF. S Afr J Bioethics Law 2018;11(1):35-37. https://doi.org/10.7196/SAJBL.2018.v11i1.618

Accepted 18 June 2019 